Tourism, Hospitality \& Event Management

João Leitão

Vanessa Ratten

Vitor Braga Editors

Tourism

Entrepreneurship

in Portugal and

Spain

Competitive Landscapes and Innovative Business Models

會 Springer 


\title{
Determinants of Profitability in the Tourism Sector in Portugal
}

\author{
Carlos Manuel Romão Travanca, Carlos Manuel Rodrigues Vieira, \\ and Elisabete Gomes Santana Félix
}

\begin{abstract}
This paper examines the impact on the profitability of firms in the Portuguese tourism sector of both internal (size, age, growth, debt) and external (real GDP growth rate, sovereign debt crisis, location) determinants. Panel data models have been employed on a large sample of small- and medium-sized firms, from 2009 to 2017, a period critically influenced by both the financial and the ensuing sovereign debt crisis in the southern European countries. Alternative profitability measures have been used and the results have been largely robust to the distinct models' specifications. The results suggested that profitability is positively affected by firm's size and age and by economic real growth rates, and negatively influenced by the firm's indebtedness ratio and the sovereign debt crisis. Firms in the main tourism regions are generally more profitable, and relatively less affected by the sovereign debt crisis, that was particularly harmful to micro-size firms.
\end{abstract}

\section{Introduction}

Portugal is currently one of the major tourism destinations in the world. The country's tourism industry has considerably developed since the 1990s, in a conscious internal effort to develop this strategic sector, partly aided by political instability in some more traditional touristic sites and also by numerous international awards that contributed to an increased visibility and attractiveness. The World Tourism Organization, a specialized agency of the United Nations, with

\footnotetext{
C. M. R. Travanca

Department of Management, University of Évora, Évora, Portugal

C. M. R. Vieira

Department of Economics, University of Évora and CEFAGE-UÉ, Évora, Portugal

e-mail: cvieira@uevora.pt

E. G. S. Félix $(\square)$

Department of Management, University of Évora and CEFAGE-UÉ, Évora, Portugal

e-mail: efelix@uevora.pt
} 